\title{
Dossier "La participación en América latina: Formas emergentes y cristalizadas de politicidad y prácticas ciudadanas": Introducción.
}

\author{
Eryka Torrejon Cardona*, Alejandro Noboa** y Mercedes Oraisón ${ }^{* * *}$
}

La participación de la ciudadanía en diferentes ámbitos de la vida social y, particularmente, en la esfera pública-política, es un tema que ocupa un lugar destacado en las investigaciones sociales de los últimos tiempos, y ha centrado el interés y la preocupación de distintas instancias de planificación de políticas públicas. Esto se observa como tendencia en todo el mundo occidental, donde la crisis de la democracia representativa ha puesto en evidencia cómo este modelo hegemónico se ha ajustado sin mayores fricciones a los intereses del neoliberalismo potenciando y generando desigualdades, abusos de poder y manipulación. Desde una racionalidad tecnocrática, se ha dejado el manejo de la política en manos de los técnicos, constriñendo los espacios de participación y deliberación auténticos, excluyendo de las negociaciones y la construcción de acuerdos a la sociedad civil, devaluando y depreciando el rol de la ciudadanía y la opinión pública. En este contexto, la mirada en torno a la participación la postula como exigencia ineludible para superar esta crisis a partir de la inclusión, la justicia y la igualdad.

América Latina es un lugar donde mirar a la hora de pensar y comprender la participación. Esta región cuenta con una larga tradición en esta materia. Desde las distintas experiencias de participación popular promovidas por Orlando Fals Borda y Paulo Freire como el medio más eficaz para que los sectores subordinados y explotados pudieran visibilizarse, hacer oír sus reclamos y reivindicaciones, tomar posesión del espacio público y generar acciones de transformación social, las

\footnotetext{
*Universidad de Antioquia (Colombia), Correo electrónico: etorrejon1@gmail.com

** Universidad de la República (Uruguay), Correo electrónico: alejandronoboasilva@gmail.com

*** Universidad Nacional del Nordeste - Centro de Estudios Sociales (Argentina). Correo electrónico: mercedesoraison@hotmail.com
} 
movilizaciones de las agrupaciones de campesinos e indígenas en su lucha por sus tierras y su identidad, hasta las diversas formas de acción colectiva y de promoción comunitaria de organizaciones territoriales hacen parte del amplio universo de experiencias de participación típicas de esta región. Estas coexisten con otras prácticas más institucionalizadas como referéndums, plebiscitos, audiencias públicas, revocatorias de mandatos, iniciativa popular, etc., que los sistemas representativos de gobierno han empezado a generar para ganar legitimidad y eficiencia en la gestión.

Algunos autores han propuesto distintas tipologías o clasificaciones de la participación para ordenar tal pluralidad de expresiones (Arnstein, 1969; Cunill, 1999; Chávez Carapia, 2006; Landau, 2008). Estas categorizaciones permiten advertir cuáles de estas prácticas participativas se conectan con el ejercicio de la ciudadanía y estimar su carácter político. Los artículos que se reúnen en este dossier permiten visualizar estas articulaciones. Los mismos analizan y valoran, desde diferentes perspectivas y en diferentes casos, los impactos de la participación a nivel objetivo y subjetivo, tanto en las redes de relaciones de la sociedad civil como en la órbita estatal. Los efectos de la participación pueden ser múltiples, tal como lo ponen en evidencia los artículos aquí presentados. Si bien es cierto que muchas experiencias llamadas participativas pueden subordinarse a la lógica del poder político administrativo y terminar siendo disciplinadoras y frustrantes en términos sociales, otras pueden llegar a convertirse en procedimientos que garanticen el éxito en la satisfacción de una demanda, la posibilidad de instalar un tema en la agenda pública y de reorientar ciertas acciones en función de los intereses de los participantes. Asimismo, y al margen de estos resultados, tal como lo señalan los autores, la participación juega un papel clave en la democratización de las instituciones y las relaciones sociales y políticas, y por su potencialidad para construir ciudadanía.

Concretamente, las contribuciones que forman parte de este dossier están vinculadas a las formas y mecanismos de participación social y autogestión local en cuatro países de América Latina; los seis artículos reflejan contextos y características sociales disímiles en las relaciones entre la sociedad civil y el Estado. Se repasan diferentes y variadas experiencias locales de la participación (institucionalizada, no institucionalizada y/o emergente), de las políticas participativas o de las expresiones subjetivas de la participación política. Los artículos en su conjunto ofrecen los usos y las adaptaciones de mecanismos -dispositivos- de participación ciudadana, del sentido y su pertinencia sociotemporal en el contexto del siglo XXI, en ciudades de diferentes tamaños y ubicaciones geográficas en la región.

Estas experiencias se reflejan como la praxis de diferentes colectivos sociales y de los gobiernos locales en respuesta -y/o al margen- de las políticas neoliberales y sus efectos en la privatización y reducción de la inversión pública en las últimas décadas, a partir de casos de estudio en ciudades de Chile, Uruguay, Argentina y Colombia. En detalle, los escenarios en que los autores presentan la materialización de estos 
procesos son las ciudades de Concordia, Viedma y la provincia de Santa Fe (casos Santo Tomé, Firmat y San Lorenzo), Córdoba y Gualeguaychú en Argentina, Valparaíso en Chile, Paysandú y Montevideo en Uruguay, y Medellín en Colombia.

Se encuentra así y desde la provincia de Santa Fe, en Argentina, el artículo de la politóloga Gisela Signorelli, titulado Presupuestos Participativos en ciudades intermedias de la provincia de Santa Fe: los casos de Santo Tomé, Firmat y San Lorenzo. Este artículo cubre tres municipios de Santa Fe -de menos de 199mil habitantes-, de segunda categoría, según la clasificación de ciudades por tamaño poblacional en Argentina; su tema central es el diseño institucional o la arquitectura institucional, como lo nombra la autora, y en esta contribución se resalta la importancia de los diseños participativos a partir de tres variables: (i) el tipo de participación, (ii) las etapas y (iii) el compromiso gubernamental. Resalta en la conclusión del artículo que los municipios de segunda categoría, como son los casos de las ciudades de Santo Tomé, Firmat y San Lorenzo, no cuentan con las mismas capacidades estatales de los municipios de primera categoría -en relación con las ciudades de Rosario y Santa Fe-, pero que estas ciudades intermedias logran potencializar la capacidad del gobierno local ante la escasez de recursos. En palabras de Signorelli, la conclusión de la sistematización de la experiencia del diseño y la implementación de los presupuestos participativos en las tres ciudades intermedias de la provincia de Santa Fe es "[...] el nivel de compromiso gubernamental con las políticas participativas, de las tres dimensiones analizadas, se vuelve trascendental en las ciudades de escala intermedia; convirtiéndose en la variable independiente para sortear las dificultades en relación al diseño y la implementación de las mismas, es decir, en relación a las capacidades estatales de los gobiernos locales". Este artículo es un referente importante para otros procesos de sistematización de los presupuestos participativos en ciudades de gran, mediano o pequeño tamaño poblacional, ya que vincula dos etapas, tanto el diseño institucional como la implementación de los presupuestos participativos; ambas etapas, en otros estudios, se han analizado en forma separada.

Mariano Suárez, en su artículo La importancia estratégica de los Presupuestos Participativos en los gobiernos locales de Córdoba, Gualeguaychú, Paysandú y Montevideo,considera que se trata de uno de los instrumentos participativos generados en Latinoamérica que luego fue exportado al resto del mundocomo la experiencia emblemática de innovación democrática. En este estudio le interesa comprender el alcance de esta herramienta de participación para crear transformaciones en el territorio, el lugar que ocupa en la estructura, en las estructuras de gobierno y en el tipo de coordinación que promueve.

El trabajo es parte de una investigación mayor que indaga los vínculos entre el PP y las tradicionales formas de representación político-partidaria, así como la forma en que este complementa o se subordina a las instituciones de la democracia representativa. Para el mencionado artículo, Suárez ha utilizado los aportes de las entrevistas a 
responsables políticos, técnicos y ciudadanos, y el organigrama oficial de los gobiernos locales. A partir de ellos, describe particularmente los casos analizados y los resultados obtenidos en cada uno. Como conclusiones, destaca algunas tendencias: los gobiernos locales no conciben al PP como una forma de gestionar participativamente los recursos públicos, sino más bien como una herramienta de movilización ciudadana. "En relación al alcance, pese a la variedad en los diseños (con más o menos deliberación, con lógicas ligadas a la competencia o al consenso en la toma de decisiones) ninguna experiencia logra generar acuerdos lo suficientemente amplios como para trascender el espacio micro, de la cuadra o la organización, generando una multiplicidad de proyectos de impacto territorial y poblacional pequeño. La idea que parece subyacer es que más allá del diseño, ciudadanos y gobernantes se sienten cómodos en este nivel. El primero logra pequeños avances, pero muy próximos a su vida cotidiana, y el segundo genera participación, pero reservando determinados temas de más complejidad para resolver de manera tradicional.

La dificultad para trascender las cuestiones micro es una de las limitaciones que advierte Suárez en los cuatro casos analizados, a los que se suman otras, como la escasa capacidad para incidir en las políticas de los proyectos que han sido aprobados y la falta de coordinación del PP con otras áreas del gobierno local.

Como el de Suárez, los otros artículos del dossier dan cuenta de la preocupación que tiene el Estado y en otro caso la sociedad civil, de buscarse formas de organización inclusivas que impliquen a los ciudadanos en la gestión de los asuntos públicos. Particularmente, en el artículo de Leonel del Prado, Las mesas de gestión en los Centros Integradores, se aborda una estrategia promovida por el Estado argentino durante la gestión kirchnerista para facilitar la participación social. Los Centros Integradores Comunitarios (CIC) se construyeron y funcionaron entre 2004 y 2015, con el propósito de articular programas territoriales de desarrollo social y la prevención primaria de la salud. El artículo focaliza su atención sobre la mesa de gestión de la ciudad de Concordia, en la que el autor realizó una observación participante durante los años 2010 y 2011. Del Prado polemiza sobre la existencia o no de implicación y participación de las comunidades a partir de la metodología participativa diseñada como central en la vida de los CIC. Estos promueven que las personas reunidas en la Mesa de Gestión definan problemas y soluciones en clave de las políticas sociales, pero luego los abandona derivándolos a actores externos a la situación problema, como asesores internacionales, técnicos y políticos. Asimismo, si "bien la Mesa de Gestión en el discurso de las nuevas políticas sociales es presentada con características que incluyen gran parte del ciclo de las políticas -planificación, ejecución, monitoreo y evaluación-, las mismas son predominantemente informativas y las decisiones de implementación de un plan, programa o proyecto en el marco de los $\mathrm{CIC}$ no es algo que se decide en una reunión de Mesa de Gestión, sino que es decidido centralizadamente desde el Ministerio de Desarrollo Social y los Municipios, y en menor medida las provincias". 
De acuerdo al artículo, no resultan ser tampoco espacios abiertos, plurales, donde los vecinos puedan concurrir con sus problemáticas a pesar de que los integran, sino que en función de las múltiples resistencias resignificados que los participantes y vecinos otorgaron a la misma resultan exclusivamente de transmisión de información y ni siquiera un componente de formación de opinión. Es en este sentido que el autor afirma que dichas mesas no resultan al final un mecanismo de participación social válido y eficaz para la canalización de los intereses y voces de la ciudadanía, ni un instrumento de democratización de las políticas.

En términos de estrategias de participación orientadas a la inclusión, el sociólogo James Vinascoplanteará la necesidad de una planeación participativa e incluyente, a partir del análisis del caso de Medellín, una ciudad interandina ubicada al noroeste de Colombia y la segunda del país en tamaño poblacional. En el artículo titulado La discapacidad, las barreras físicas y el ejercicio ciudadano en la lucha por el derecho a la ciudad en Medellín, Colombia (2007-2015), Vinasco centra su contribución en la necesidad de una planeación participativa de la ciudad para la inclusión de la población con discapacidad. La hipótesis del autor es que "las personas con discapacidad implementan diversas estrategias y acciones sociopolíticas para incidir sobre la planeación que la administración pública hace de los espacios de la ciudad, con el fin de superar condiciones de dominación y exclusión, y la reivindicación de su condición de ciudadanos". El autor inicia su artículo con una presentación paralela entre los modelos de la planeación de la ciudad de Medellín, y las etapas y evolución de las políticas públicas de la población con discapacidad en las primeras décadas del siglo $X X I$. En esta presentación panorámica indica que la planeación de la ciudad en forma reciente no ha logrado incluir a la población con discapacidad. Así, y en forma retrospectiva, nos muestra cómo la condición de la discapacidad ha sido una construcción social resultado de un conjunto de ideas sociales, como plataformas de un orden y una jerarquía social. Los datos en forma de testimonios de los integrantes de las organizaciones de personas con discapacidad los vincula con los aportes de Henri Lefebvre, Michael Foucault, David Harvey y Jordi Borda; para finalizar, valida la hipótesis al demostrar cómo las prácticas espaciales de las personas con discapacidad -discursos y acciones sociales en los espacios públicos de Medellín- trascienden la demanda de accesibilidad física y se instauran como acciones colectivas de una ciudadanía que reivindica las discapacidades - $u$ otras capacidades- como una condición y un derecho identitarios.

James Vinasco rescata la capacidad reivindicativa de las organizaciones de base de la población con discapacidad para demandar tanto la accesibilidad universal a los espacios públicos como el derecho y el reconocimiento de la condición de discapacidad como una identidad colectiva.

El artículo de Retamal Canto, Innovación Social: una experiencia de trabajo colectivo entre la Universidad de Playa Ancha y su territorio, es interesante para visualizar cómo 
una experiencia participativa fortalece lazos entre distintos actores de la sociedad civil. En él se describe un proyecto de innovación social llevado adelante por la mencionada universidad estatal a partir de diversas instancias participativas en las que la comunidad universitaria y los actores sociales intercambiaron saberes, necesidades y oportunidades.

La experiencia se trató de la elaboración participativa de una cartografía socioterritorial a la que el autor describe como "un esfuerzo por generar procesos colaborativos y construcción colectiva de conocimiento, para la caracterización del espacio habitado y la generación de acciones que permitan mejorar la calidad de vida de sus habitantes".

Su ejecución comienza en el año 2014, destacándose dos instancias de desarrollo con fuerte enfoque territorial. La primera, la Unidad de Innovación Social (UIS), como área para la gestión y coordinación de instancias de vinculación y relación bidireccional entre la comunidad universitaria y el territorio. Y la segunda, la Mesa Territorial de Desarrollo (MTD), espacio de participación colaborativa entre diversos actores del barrio, representantes de organizaciones sociales (funcionales y territoriales) e institucionales del ámbito local, coordinada por el equipo profesional de la Unidad de Innovación Social; en esta mesa se han establecido redes de cooperación y lazos de confianza en este proceso de articulación, bajo el prisma de la innovación social.

El proyecto se basó en el postulado de que el hecho de identificar el espacio local y hacerlo parte del territorio implica comprender la dinámica social de relaciones entre vecinos de un mismo barrio, lo cual enriquece la experiencia de generación de conocimiento, permitiendo el encuentro de saberes entre los actores sociales del territorio y la Universidad. Se realizó un total de 28 salidas al territorio para levantar información conjunta entre el equipo del Observatorio de Innovación Social y actores sociales de la Mesa Territorial de Desarrollo, estableciéndose que, para cada Macrozona (4), se considerasen siete microzonificaciones, por lo que el proceso en terreno y de digitalización de la información tuvo una duración de siete meses.

Tal como lo destaca el autor, la cartografía socioterritorial como metodología se ha enriquecido enormemente al poseer en sus contenidos la mirada socioespacial y simbólica que los habitantes construyen sobre el territorio. Asimismo, la experiencia permitió construir un significativo diálogo de saberes que se ponen a disposición entre la universidad y el territorio, permitiendo el abordaje de diferentes temáticas disciplinares que pueden ser sustentadas por la universidad en pro del compromiso público y con el territorio.

En el artículo de Sandra Poliszuk, Estructuras del sentir en contextos de politicidad juvenil, se describen los procesos de comunicación y subjetivación involucrados en las prácticas de participación política de dos grupos estudiantiles de la ciudad de Viedma, Río Negro. 
Este trabajo profundiza en un mundo que a pesar de todo aún permanece poco conocido para la academia. La estructura del sentir es una propuesta conceptual planteada por Raymond Williams a modo de hipótesis cultural, como un intento por comprender los emergentes sociales que se expresan en nuevas formas de sentir y pensar frente a los sentimientos ya "precipitados" o articulados de modo pleno en las instituciones de un período determinado.

Estas, las estructuras del sentir, se analizan en las conciencias prácticas de los grupos estudiados, es decir, en aquellas manifestaciones de conducta donde ellos expresan con acciones sus esquemas mentales, en este caso una agrupación estudiantil universitaria y un grupo de estudiantes secundarios de una radio escolar comunitaria. En este sentido,se trabaja sobre tres dimensiones o niveles de análisis: a) estructural, que consistió en relevar los espacios de interacción y encuentro de los jóvenes y los equipamientos tecnológicos digitales utilizados; b) situacional, centrado en estudiar los contextos sociocultural y comunicacional en los que se desenvuelven los jóvenes; y c) simbólico, consistente en analizar la producción de sentidos que posibilitan a los jóvenes estar juntos y el significado que adquieren la tecnología y los medios de comunicación en esos procesos. La población para este estudio fueron los jóvenes de Viedma, provincia de Río Negro, que integren diversas agregaciones juveniles y transiten diferentes etapas de la educación universitaria y en los últimos años de la educación media.

La hipótesis de trabajo es que la experiencia de tiempo-espacio y la dimensión comunicativa de la intimidad que se vivencia en las redes sociales digitales impactan, crecientemente, en los procesos de cambio de las formas de sentir la militancia estudiantil.

Para la observación, se valió de distintas técnicas de recogida de datos como la encuesta, entrevistas individuales en profundidad, entrevistas colectivas semiestructuradas, observación no participante y creación de espacios virtuales de intercambio entre jóvenes de Viedma y Mexicali.

Se concluye en el artículo que la política es vivida crecientemente por muchos de estos jóvenes en torno a identificaciones políticas provisionales y frágiles más que a la construcción de alteridades relativamente estables. "Esta característica se expresa, entre otros aspectos, en los modos de autonombrarse como grupo, ya sea fusionando conceptos, aparentemente contradictorios entre sí, que ponen en tensión sus sentidos hegemónicos o los subvierten, como así también apelando a nombres de la vida cotidiana o mezclando lenguajes que desestabilizan e incomodan los modos tradicionales de reconocimiento político".

Es así que las redes sociales digitales pasan a constituirse, más que en un canal de expresión, en un escenario configurativo de las prácticas políticas concretas, de las formas organizativas y de los procesos complejos de la construcción identitaria juvenil, donde se disputan los sentidos y se resignifican las diferentes trayectorias grupales, 
resultando una verdadera plataforma de construcción de significaciones para estos grupos. Por lo tanto, resulta un mecanismo creativo de organización de los jóvenes a partir de la observación de las formas del sentir, constituyéndose en un ejemplo interesante y exitoso de construcción ciudadana de la participación social.

En continuidad con el artículo anterior, el trabajo Sentidos políticos del estar juntos: jóvenes, grupalidades, politicidad, de Andrea Bonvillani, retoma el interés por comprender el modo en que los jóvenes significan sus prácticas políticas. En este caso, "explorar algunas experiencias expresivo-recreativas de colectivos juveniles de la ciudad de Córdoba (Argentina), para establecer articulaciones, discontinuidades y mixturas que permitieran dar cuenta de las relaciones entre lo que se denomina 'grupalidades juveniles' y 'politicidad popular' en el escenario local".

Dice Bonvillani que la politicidad de los jóvenes de sectores populares se encuentra atravesada por lo que ha denominado "gramática de la necesidad", que empuja hacia la procuración cotidiana de recursos -materiales y simbólicos- que permiten el mantenimiento de la propia vida. De esta forma, se configuran modos de participación política con un fuerte anclaje en el lugar donde inmediatamente se despliega la cotidianeidad: el barrio.

En su investigación, la autora ha analizado distintas formas organizativas en el espacio del territorio comunitario y experiencias participativas que los jóvenes de sectores populares desarrollan en comedores y roperos comunitarios, grupos culturales en bibliotecas, talleres artísticos barriales, consideraciones significativas para dar cuenta de sus formas actuales de politización.

El diseño de investigación a partir del cual se desarrolló el estudio que origina este trabajo fue de tipo cualitativo, ya que se orientó a reconstruir los sentidos que los sujetos jóvenes les otorgan a sus experiencias en las dinámicas colectivas de anclaje territorial. El trabajo de campo se desarrolló en 2011, en distintos talleres culturales para jóvenes de sectores vulnerables coordinados por una fundación local.

El artículo concluye que los sentidos políticos de las prácticas culturales de los jóvenes tienen un sentido inmanente y que "la productividad política del estar juntos se define por sí misma en la potencia del encuentro, en el 'estar-ahí-con-otros', más allá que de ese vínculo construido procesualmente resulten (contingentemente) otras posibilidades de politización". Aparecen, además, en tensión objetivos vinculados al desarrollo de recreación, expresión y sociabilidad, y otros en los cuales la búsqueda de un sentido político parece articular sus prácticas, "objetivando demandas que condensan la cuestión social en la que se ubican como damnificados por la injusticia social práctica".

Se observa, finalmente, que el sentido político que atraviesa de manera clara algunas de estas acciones culturales juveniles se expresa en la producción colectiva y democrática de representaciones sociales que supongan formas instituyentes de pensar, significar y sentir el ser un joven de sector popular en Córdoba. Una disputa 
simbólica que supone por parte de ellos un trabajo político de impugnación de las imágenes y creencias que circulan hegemónicamente sobre ellos, cargadas de valoraciones altamente negativas que se expresan en cadenas significantes del tipo joven-pobre-vago-ladrón-drogadicto.

Los artículos del fructífero dossier revelan una muestra de las múltiples y diversas experiencias de participación en América Latina, que implican a distintos actores sociales y a diferentes estamentos estatales. Dan cuenta, además, de los esfuerzos desplegados por las comunidades y ciudadanos para transformar situaciones de vulnerabilidad y desigualdad social, para democratizar las relaciones sociales y construir un sentido de lo público.

\section{Bibliografía}

Arnstein, Sherry R. (1969).A ladder of citizen participation. Journal of the American Institute of Planning, 35, 3, pp. 216-224.

Cunil, N. (1999). La reinvención de los servicios sociales en América Latina: algunas lecciones de la experiencia.Revista del CLAD "Reforma y Democracia",13, Caracas.

ChávezCarapia, C. (2006).Participación social: retos y perspectivas. México: Plaza y Valdez.

Landau, M. (2008).Política y participación ciudadana. Buenos Aires: Miño y Dávila. 